\title{
Splenic Trabecular Artery
}

National Cancer Institute

\section{Source}

National Cancer Institute. Splenic Trabecular Artery. NCI Thesaurus. Code C49775.

The arteries branching from the splenic artery within the trabeculae of the spleen. 